ARTICLE

https://doi.org/10.1038/s41467-019-09054-8

\title{
Colorless-to-colorful switching electrochromic polyimides with very high contrast ratio
}

\author{
Qiang Zhang ${ }^{1}$, Chou-Yi Tsai ${ }^{1}$, Lain-Jong Li id ${ }^{2}$ \& Der-Jang Liaw ${ }^{1}$
}

Colorless-to-colorful switching electrochromic polymers with very high contrast ratio are unattainable and attractive for the applications of smart wearable electronics. Here we report a facile strategy in developing colorless-to-colorful switching electrochromic polyimides by incorporating with alicyclic nonlinear, twisted structures and adjusted conjugated electrochromophores, which minimize the charge transfer complex formation. It is noted that, by controlling the conjugation length of electrochromophore, the colorless-to-black switching electrochromic polymer film (PI-1a) exhibites an ultrahigh integrated contrast ratio up to $91.4 \%$ from 380 to $780 \mathrm{~nm}$, especially up to $96.8 \%$ at $798 \mathrm{~nm}$. In addition, PI-1a film with asymmetric structure also demonstrates fast electrochemical and electrochromic behaviors (a switching and bleaching time of $1.3 \mathrm{~s}$ and $1.1 \mathrm{~s}$, respectively) due to the loose chain stacking, which provides more pathways for the penetration of counterion. Moreover, the colorless-to-black EC device based on PI-1a reveals an overall integrated contrast ratio up to $80 \%$.

\footnotetext{
${ }^{1}$ Department of Chemical Engineering, National Taiwan University of Science and Technology, 10607 Taipei, Taiwan. ${ }^{2}$ School of Materials Science and Engineering, University of New South Wales, 2052 NSW, Australia. These authors contributed equally: Qiang Zhang, Chou-Yi Tsai. Correspondence and requests for materials should be addressed to D.-J.L. (email: liawdj@gmail.com or liawdj@mail.ntust.edu.tw)
} 
$\mathrm{N}$ on-emissive electrochromic polymers (ECPs) received great attention recent decades due to their low-power consumption, facile color tunablility through molecular design $^{1}$, high processability of highly flexible and rollable displays compared to their inorganic counterparts ${ }^{2-5}$. In developing EC display panels, it needs to include non-emissive chromophores as pixels or superimposed to recreate other different desirable colors $^{3}$, which requires precise control of the colors displayed in terms of their hue, saturation, intensity, and their brightness. However, the colorless-to-colorful ECPs, especially the colorlessto-black ECPs with ultrahigh contrast ratio over the entire visible region, are still unattainable due to the extreme difficulties in design of completely reverse absorptions (transmittance) in transmissive and colored states ${ }^{5,6}$. In addition, the superposition of several desirable colors by color-mixing theory ${ }^{7}$ even deepens the color of EC device in transmissive state. Therefore, in spite of the efforts in developing various colorful ECPs (i.e., black ECPs) ${ }^{1-11}$, both cathodically and anodically coloring ECPs still showed low transmittance in their transmissive states ${ }^{8-11}$. For instance, Reynolds et al. ${ }^{3,5,6}$ initiated the development of blackto-transmissive ECPs through donor-acceptor design, however, weak absorption of these fully oxidized ECP films ${ }^{5}$ in the visible region still existed. In addition, another strategy was developed by Lee et al. and Beverina et al., transmissive-to-black ECPs were obtained by incorporating multichromophores, which had the advantages of superposition of different absorptions from different electrochromophores ${ }^{8-11}$. But it was difficult to control over the absolute redox potential in some cases at the respective electrodes $^{11}$ and the long conjugation also revealed low transmittance in transmissive states ${ }^{8-11}$. Moreover, thick viologen films could be used as colorless-to-black/gray EC materials, however, the thick film exhibited low transmittance in neutral states $^{12}$. Therefore, the development of completely colorless ECP, especially in the field of colorless-to-black ECP, is still remained the most challengeable problem in the field of ECPs up to date.

For decades, triarylamine (TAA) and its derivatives have been used for wide applications in optoelectronic devices ${ }^{13-17}$. In the field of ECPs, TAA showed great advantages because most of their absorptions located at UV region in neutral state ${ }^{18-20}$, which enabled the development of completely colorless ECP films. In addition, TAAs exhibited tunable colors in oxidized states by adjusting conjugation length, which facilitated the design of various colors (including black stage) ${ }^{18-23}$. Therefore, TAA could be considered as the most promising candidates for the colorless-to-colorful ECPs (especially the colorless-to-black
ECPs with ultrahigh contrast ratio). On the other hand, based on our previous report ${ }^{24}$, transparent-to-colorful EC polyimides could be developed due to the conjugation break by the imide groups along the main chain. However, the charge transfer complex (CTC) formation in polyimides always generated yellow or brown colors in polyimide films ${ }^{25}$, which may hinder the development of colorless polyimide films.

In this study, we introduced a facile strategy that colorless-tocolorful ECPs, exemplified by PI-1a (colorless-to-black) and PI-2a (colorless-to-blue), could be achieved through preparing polyimides with specific molecular designs. In particular, polyimides were polymerized by twisted ${ }^{26}$ TAA diamines and alicyclic nonlinear diimides, which significantly reduced the CTC formation and enhanced the visible transparency in neutral state. On the other hand, the EC colors were tuned by adjusting the conjugations within an adjusted length, enabling various colorful electrochromism (including black stage) in oxidized states and colorless appearance in neutral states ${ }^{19}$. In addition, EC behavior of PI-1a with asymmetric pendant groups is faster than that of PI-2a, which was related with the looser chain stacking and resulting faster penetration of counterion ${ }^{19,27}$. The facile strategy in developing colorless-to-colorful ECPs with ultrahigh contrast could be especially practical in EC displays and optical areas.

\section{Results}

Synthesis and characterization. All the chemical structures of polyimides were shown in Figs. 1 and 2. They were prepared via coupling reaction and polycondensation, the synthetic routes (see Supplementary Figure 1, Supplementary Figure 6 and Supplementary Figure 8) and characterizations (see Supplementary Figures 2-5, Supplementary Figure 7, Supplementary Figures 910) were described in Supplementary Methods.

Facile strategy of colorless-to-colorful ECPs. We show that the facile strategy in developing colorless-to-colorful EC polyimides is by incorporating alicyclic nonlinear diimide and twisted TAAcontaining diamine (see Fig. 1a), exemplified by colorless-toblack (PI-1a, see Fig. 2a) and colorless-to-blue (PI-2a, see Fig. 2a) switching ECPs in this study.

Superior transmittance. Figure $1 \mathrm{~b}$ shows the transmittance spectra of polyimide films (PI-2a and PI-2b) using alicyclic nonlinear HTA-PPD and 4,4'-(hexafluoroisopropylidene) diphthalic anhydride (6FDA, a widely used dianhydride for a

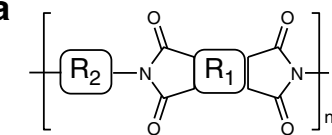

$R_{1}$ : Alicyclic nonlinear dianhydride $\mathbf{R}_{\mathbf{2}}$ : Twisted aromatic electrochromophore

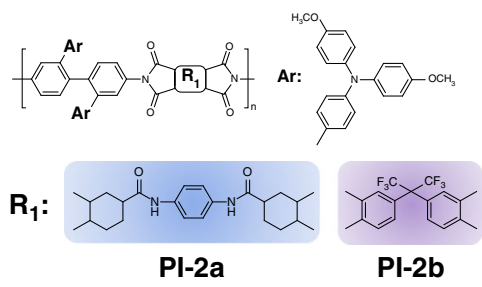

b

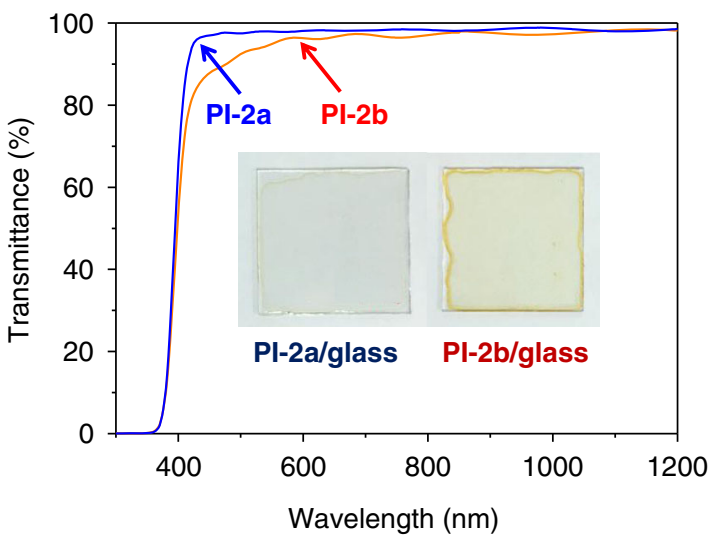

Fig. 1 Polyimide structures and comparison of their transmittance spectra. a General chemical formula of transparent polyimides incorporation of nonlinear alicyclic diimide and twisted TAA-containing diamine. b Transmittance spectra of PI-2a and PI-2a films 
a<smiles>[R6]C1CCC(C)(C)CC1N1C(=O)C2CCC(C(=O)Nc3ccc(NC(=O)C4CCC5C(=O)N(C)C(=O)C5C4)cc3)CC2C1=O</smiles>

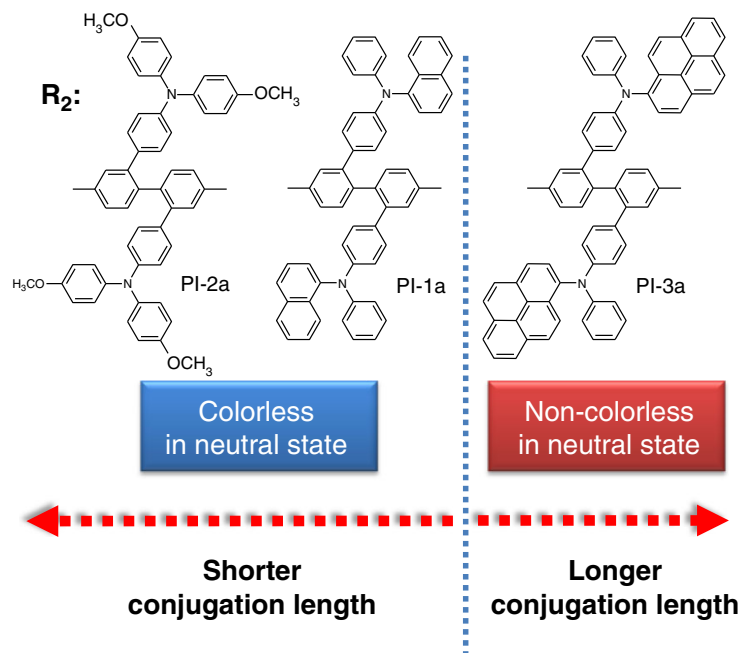

b

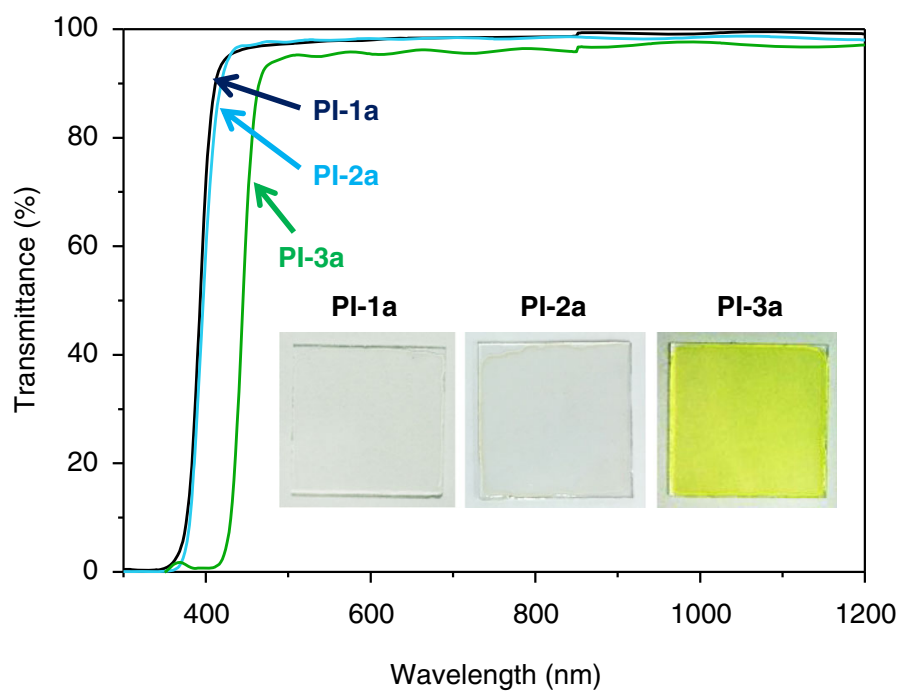

Fig. 2 EC polyimide structures and their transmittance spectra. a Chemical structures of PI-1a, PI-2a, and PI-3a. b Transmittance spectra of PI-1a, PI-2a and PI-3a films on ITO glass. Insert photographs show the colors of PI-1a, PI-2a, and PI-3a films

preparation of transparent polyimides $)^{28}$. PI-2a film was colorless and transparent while PI-2b film was slightly red-brown (see Supplementary Figure 11a), the enhancement of PI-2a film transmittance spectra in the range of $400-600 \mathrm{~nm}$ (see Fig. 1b) could be attributed to the inhibited CTC, resulted from the nonlinear (cis, cis)-alicyclic moieties of HTA-PPD (characterized in Supplementary Figure 4$)^{29}$. The photoluminescence (PL) excitation maps (PLE) showed an intensive PL of PI-2a film (see Supplementary Figure 11c) and a quenched PL of PI-2b film (see Supplementary Figure 11d), indicative of the CTC absence of PI2a film ${ }^{30,31}$, which was attributed to the nonlinear cyclohexyl moiety of HTA-PPD ${ }^{32}$.

EC behavior of PI-1a and PI-2a films. Three kinds of TAA derivatives with different conjugation lengths ( $(1)(N$-phenyl- $N$ phenyl)naphthalen-1-amine, (2) bis(4-methoxy- $N$-phenyl)aniline, and (3) ( $N$-phenyl- $N$-phenyl)pyrene-1-amine, as shown in Fig. 2a) were bonded to the meta-positions of diphenyldiamine as pendant groups to form noncoplanar structures. As revealed in Fig. $2 a, b$, the polyimide film became yellow when the conjugation length of pendant group extended to $N$-phenyl- $N$-phenyl)pyrene1-amine, while the PIs with shorter conjugations were colorless in neutral state. In particular, Fig. $2 b$ showed the photographs of colorless PI-1a and PI-2a films in neutral state. The electronic properties of PI-1a and PI-2a were summarized in Supplementary Table 1.

The EC behaviors of PI-1a and PI-2a films were investigated by spectroelectrochemistry experiments. In the neutral state (adjust the applied potential to $0 \mathrm{~V}$ ), both polyimide films showed strong absorption peaks in the UV region, which were characterized as the $\pi-\pi^{*}$ transition of diamine moiety (shown in Fig. $\left.3 a, b\right)^{19}$. When the applied potential increased from 1.0 to $1.3 \mathrm{~V}, \mathrm{PI}-1 \mathrm{a}$ film begin to oxidize and a board absorption peak at $796 \mathrm{~nm}$ continuously raised, exhibiting strong absorption in the entire visible region. Meanwhile, PI-2a film oxidized when the applied potential is between 0.9 and $1.2 \mathrm{~V}$ (shown in Fig. 3b) and a narrow absorption peak at $760 \mathrm{~nm}$ continuously increased. The oxidized PI-2a film showed weaker absorption intensity in the blue region than that in the green and red regions and almost no absorption in the near-IR region. The phenomena of broader absorption peak of oxidized PI-1a film (compared to PI-2a film) could be attributed to the longer conjugation length, which enhanced charge carrier delocalization compared to oxidized PI2a film ${ }^{19}$.

The transmittance spectra and color changes of PI-1a and PI2a films were also investigated. As shown in Fig. $3 c$, d, the transmittance spectra of PI-1a and PI-2a films in neutral states were both higher than $97 \%$ over most of the visible region, indicative of transparent and colorless appearance. When the applied potential on PI-1a film increased from 0 to $1.3 \mathrm{~V}$, the transmittance spectra of PI-1a film dramatically decreased (see Fig. 3c) over the entire visible region and exhibited a black stage in the fully oxidized state. On the other hand, PI-2a film revealed a colorless-to-blue switching when the applied potential increased from 0 to $1.2 \mathrm{~V}$ (see Fig. $3 \mathrm{~d}$ ) due to its weak absorption in blue region (see Fig. 3b), viz. nearly half transmittance $(\sim 48 \%)$ at $470 \mathrm{~nm}$ still existed. Notably, the integrated contrast ratios $\left(\Delta \% T_{\text {int }} \text { : integrated from } 380 \text { to } 780 \mathrm{~nm}\right)^{33}$ of PI-1a and PI-2a were $91.4 \%$ and $81.2 \%$ (summarized in Table 1 ), respectively, which were much higher than that in literature ${ }^{33}$.

In order to investigate the charge transfer behaviors in PI-1a and PI-2a films, electrochemical response behaviors of PI-1a and PI-2a films were measured via scan rate alternation experiments and electrochemical impedance spectroscopy (EIS). First, the scan rate alternation experiments (from 10 to $100 \mathrm{mV}$ ) and the resulting peak currents vs. (scan rate) $)^{1 / 2}$ of PI-1a and PI-2a films were shown in Fig. $4 a, b$, respectively. In particular, the diffusion coefficient of counterion $\left(\mathrm{ClO}_{4}^{-}\right)$in both films could be analyzed according to the Randles-Sevcik equation (Eq. (1)) $)^{34}$.

The current maximum value $\left(i_{\mathrm{p}}\right)$ is proportional to the square root of scan rate $\left(v^{1 / 2}\right)$, with a slope of $k n^{3 / 2} A D^{1 / 2} c^{34}$. Therefore, $D$ value (diffusion coefficient) of PI-1a $\left(1.69 \times 10^{-7} \mathrm{~cm}^{2} \mathrm{~s}^{-1}\right)$ was higher than that of PI-2a films $\left(5.41 \times 10^{-8} \mathrm{~cm}^{2} \mathrm{~s}^{-1}\right)$, indicating that the counterion $\left(\mathrm{ClO}_{4}^{-}\right)$diffusion in PI-1a film was faster than that in PI-2a film ${ }^{19}$. In addition, differential pulse voltammetry (DPV) of PI-1a and PI-2a films were performed and the results 

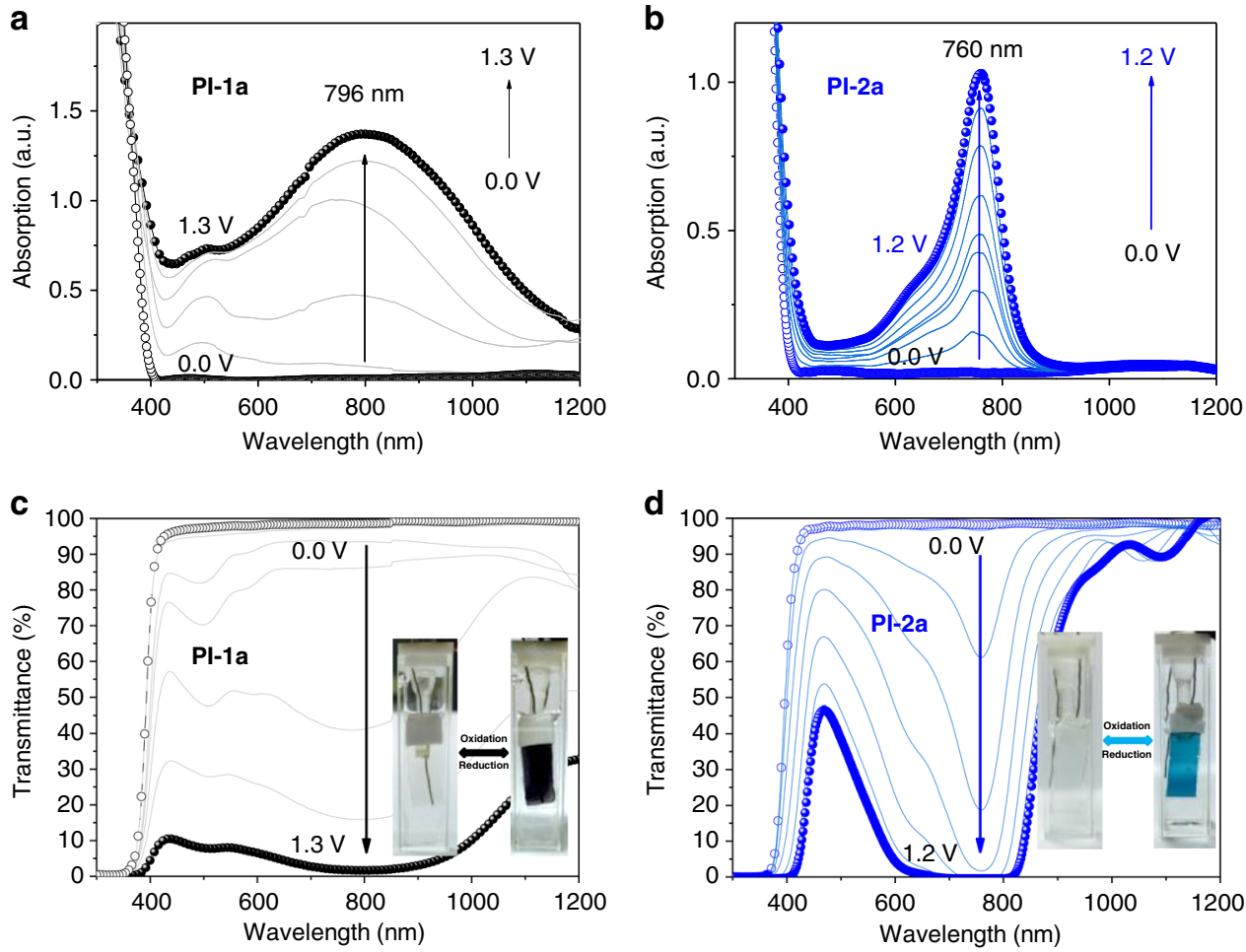

Fig. 3 Electrochromic behaviors of EC Polyimides. a Absorption spectra of PI-1a. b Absorption spectra of PI-2a films. c Transmittance spectra of PI-1a. d Transmittance spectra of PI-2a films on ITO substrate. The insert photographs show the color changes of PI-1a and PI-2a films when the applied potential are changed from 0 to $1.3 \mathrm{~V}$ and 0 to $1.2 \mathrm{~V}$, respectively

\begin{tabular}{|c|c|c|}
\hline & PI-1a & PI-2a \\
\hline $\begin{array}{l}\Delta \% T\left(\lambda_{\max }\right) \\
\Delta \% T_{\text {int }}(380-780 \mathrm{~nm}) \\
\eta\left[\mathrm{cm}^{2} \mathrm{C}^{-1}\right] \text { at } \lambda_{\max } \\
T_{400}(\%)\end{array}$ & $\begin{array}{l}96.8 \%(\text { at } 798 \mathrm{~nm}) \\
91.4 \% \\
99(\text { at } 798 \mathrm{~nm}) \\
72\end{array}$ & $\begin{array}{l}96.2 \%(\text { at } 760 \mathrm{~nm}) \\
81.2 \% \\
78(\text { at } 760 \mathrm{~nm}) \\
65\end{array}$ \\
\hline
\end{tabular}

were shown in Supplementary Figure 12, which indicated that no significant electron coupling could be observed. Moreover, we also performed the electrochemical impedance spectroscopy (EIS) on PI-1a and PI-2a films, as shown in Fig. 4c. The higher slope of the PI-1a film at low frequency region indicated that the charge transfer in PI-1a electrochemical system was faster than that in PI-2a electrochemical system ${ }^{19}$.

Fast EC behavior in PI-1a film. To understand the origin of the faster ionic transporting behavior and accelerated EC behavior of PI-1a film, SEM cross-section images of PI-1a and PI-2a films were measured (see Fig. 4d), and the thickness of PI-1a and PI-2a were 730 and $360 \mathrm{~nm}$, respectively. Since we deposited the same amount of PI-1a and PI-2a on ITO within the same area $(2 \mathrm{~cm} \times$ $2 \mathrm{~cm})$ and the molecular weight of single repeating unit $\left(M_{0}\right)$ of PI-1a $\left(M_{0}=1203\right)$ and PI-2a $\left(M_{0}=1223\right)$ were similar, the film thicknesses mainly depended on the polymer chain stacking property and were inversely proportional to the film density (Eq. (2) $)^{35}$.

The calculation methods of densities of PI-1a and PI-2a films were according to Methods and Supplementary Figure 13, which indicated the densities of two films (the homogeneously middle part) were 3.0 and $6.7 \mathrm{~g} \mathrm{~cm}^{-3}$, respectively. The density results demonstrated that PI-1a formed a more loosely stacking polymer film. The looser chain stacking of PI-1a could be attributed to the asymmetric ( $N$-phenyl- $N$-phenyl) naphthalen-1-amine moiety ${ }^{36}$, which generated more disordered chain entanglement (Supplementary Figure 17) and free volumes ${ }^{37}$. In addition, the SAXS and XRD of PI-1a and PI-2a films were performed and the results were shown in Supplementary Figure 14, indicating that both of films were amorphous and there were no obviously close chain stacking ${ }^{38-40}$.

Generally, faster electrochromic response behaviors could be influenced by several factors: (1) higher conductivity of EC films ${ }^{41}$, (2) composition of electrolyte ${ }^{42}$, and (3) faster counterion diffusion $^{27,43}$. When considering factor (1), polyimides are nonconjugated polymers and always used as high performance engineering plastic insulator (such as DUPONT ${ }^{\mathrm{sin}} \mathrm{KAPTON}^{\circledR}$ ). In addition, the large $\operatorname{arc}\left(Z^{\prime \prime}(\Omega): 0 \sim 2500\right)$ in the low frequency in EIS (Fig. 3c) demonstrated that both of the polyimide films exhibited very large resistence ${ }^{44,45}$, indicating that the difference in conductivity of PI-1a and PI-2a films could not be taken into consideration. That is, in principle, the two polyimide films are insulators having low conductivity. Factor (2) could also be omitted because PI-1a and PI-2a films are both tested in the same electrolyte $(0.1 \mathrm{M}$ TBAP/acetonitrile). In this contest, the faster electrochemical and electrochromic behavior might be considered as the faster counterion diffusion (factor (3)). Therefore, we further measured the different morphologies of PI-1a and PI-2a films by AFM (Supplementary Figure 15), which demonstrated that both films possessed similar roughness (below $1 \mathrm{~nm}$ ). So the faster EC behaviors were not resulted from different morphologies. Based on the above discussion and results from SEM, CV, and EIS, we concluded that the faster counterion diffusion in PIla could be resulted from its lower density and higher free volume, providing more pathways for the penetration of counterion $\left(\mathrm{ClO}_{4}^{-}\right)^{19}$. 

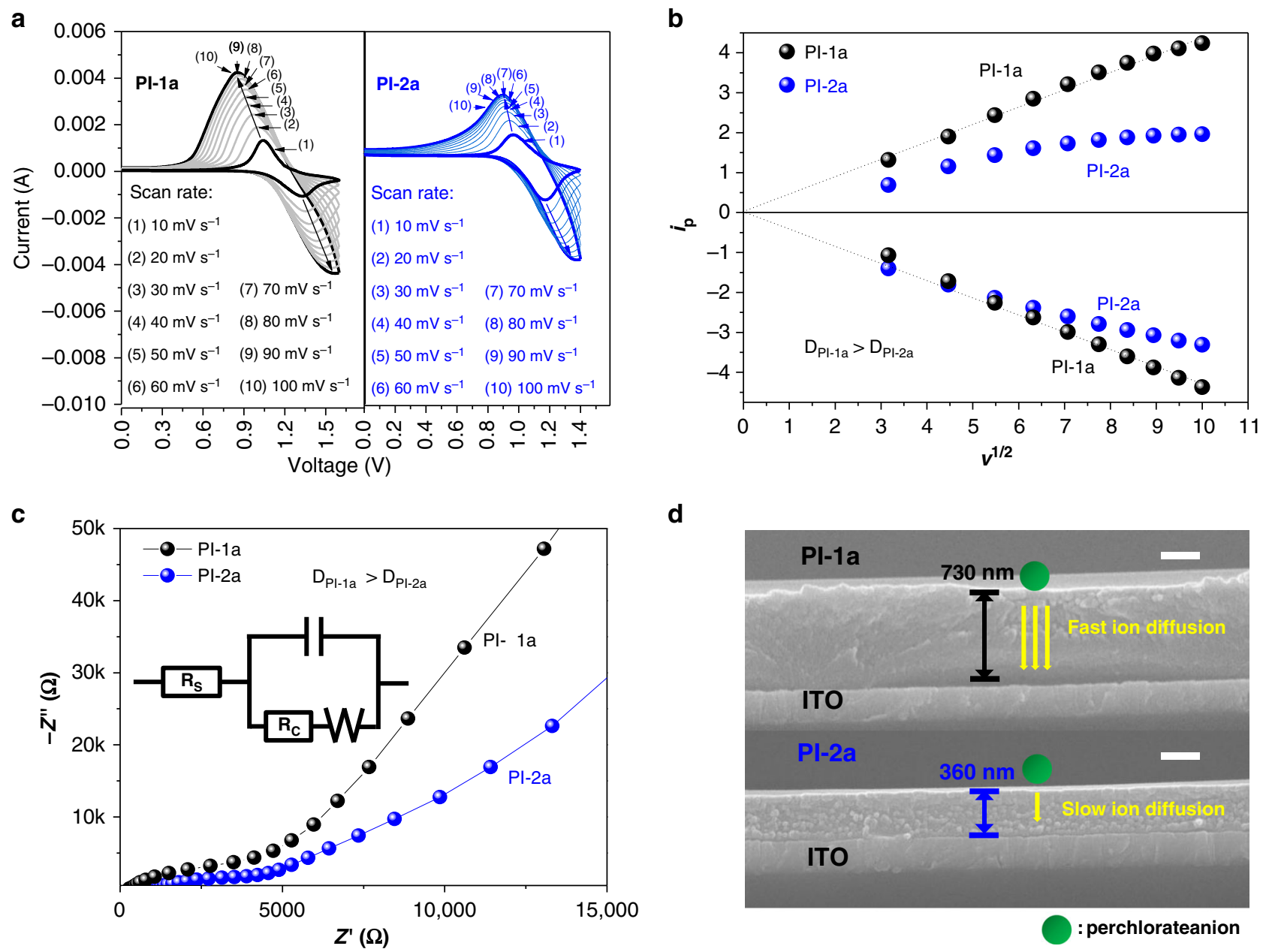

Fig. 4 Electrochemical behaviors of EC Polyimides. a CVs of PI-1a and PI-2a films at different scan rates. $\mathbf{b}$ Plots of the peak current densities vs. (scan rates) $)^{1 / 2}$ of $\mathrm{PI}-1 \mathrm{a}$ and $\mathrm{PI}-2 \mathrm{a}$ films. c Nyquist diagrams of $\mathrm{PI}-1 \mathrm{a}$ and $\mathrm{PI}-2 \mathrm{a}$ films in $0.1 \mathrm{M} \mathrm{TBAP} / \mathrm{CH}_{3} \mathrm{CN}$ solution. d Cross-sectional SEM images of PI-1a and PI-2a films. The scale bar is $200 \mathrm{~nm}$
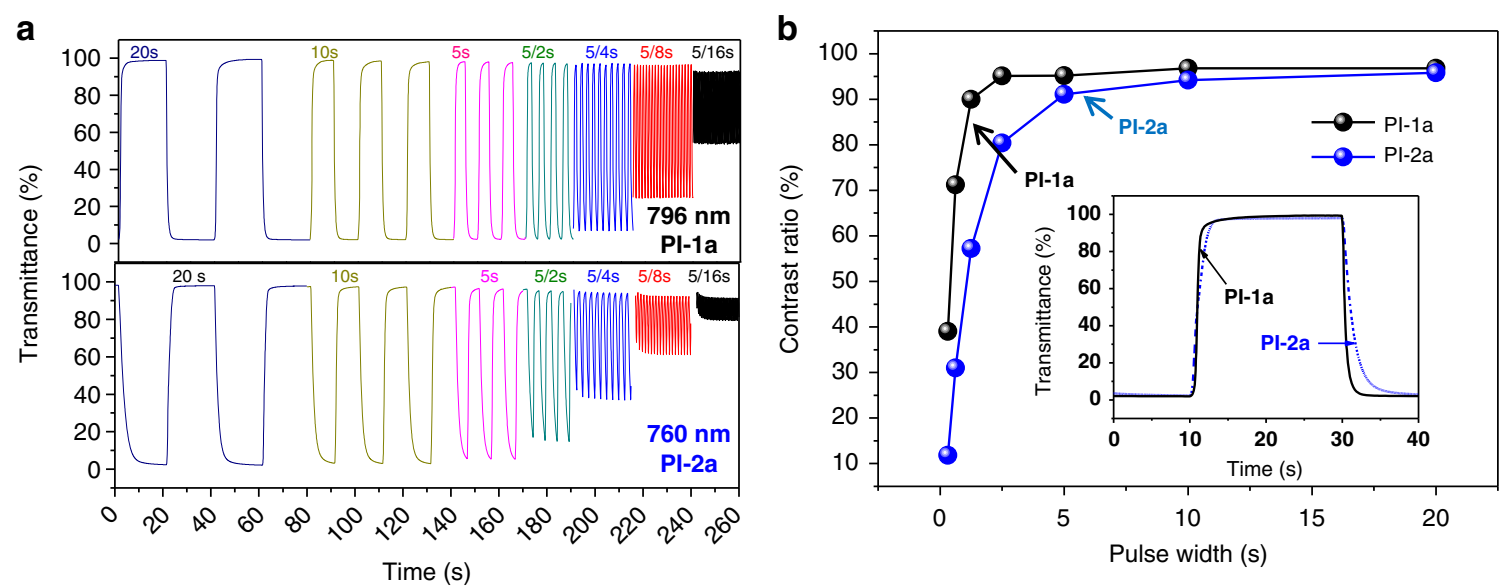

Fig. 5 Transmittance changes of EC Polyimides. a Transmittance changes ( $760 \mathrm{~nm}$, with decreasing pulse width from 20 to $5 / 16$ s) of PI-1a and PI-2a films with applied potential between $0-1.3$ and $0-1.2 \mathrm{~V}$, respectively. b Contrast ratios vs. pulse width. Insert Figure shows the faster EC behavior of PI-1a

Further evidence of the faster charge transfer behavior in PI-1a film was demonstrated by the transmittance changes. As shown in Fig. 5a, continuous changes of pulse width were given to PI-1a and PI-2a films, their transmittance changes at $796 \mathrm{~nm}$ and $760 \mathrm{~nm}$ were monitored, respectively. The initial contrast ratio (with $20 \mathrm{~s}$ pulse width) of PI-1a and PI-2a films were both around
$97 \%$. The contrast ratio of PI- 1 a film decreased to $96 \%, 95 \%, 95 \%$, $90 \%, 72 \%$, and $39 \%$ when the applied pulse widths shortened to $10,5,5 / 2,5 / 4,5 / 8$, and $5 / 16 \mathrm{~s}$, respectively. On the contrary, the contrast ratio of PI-2a film decreased to $94,91,80,57,32$, and $12 \%$ with the same applied pulse widths. Significantly, the higher contrast ratios of PI-1a film indicate that the PI-1a film has a 
a

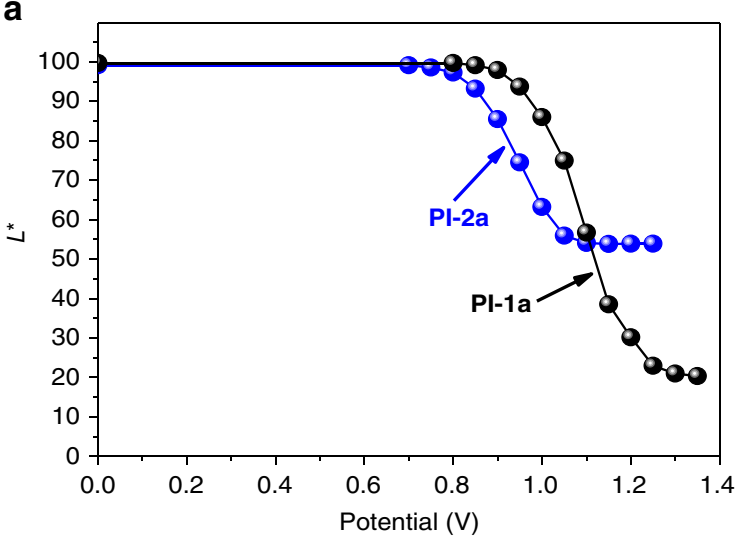

b

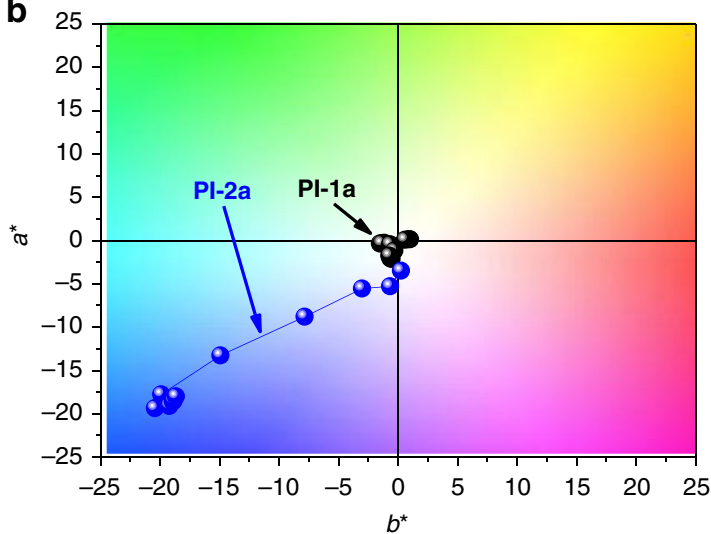

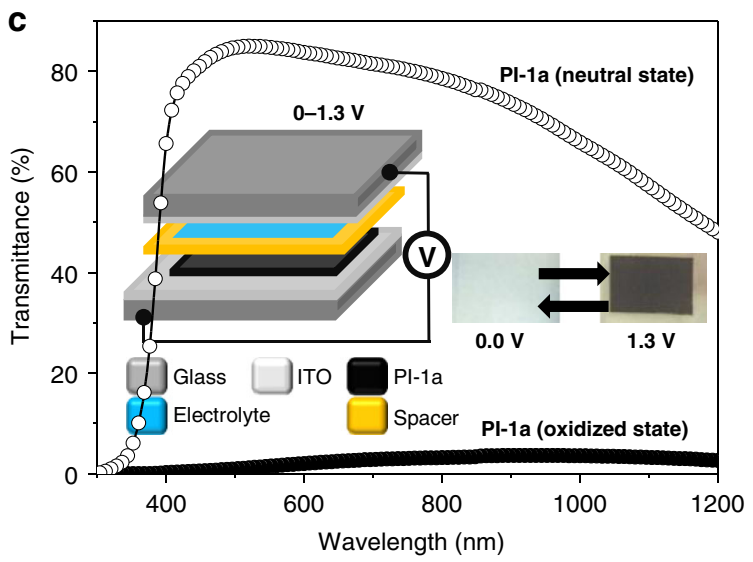

Fig. 6 Color space results and EC device. a Lightness values and $\mathbf{b} a^{\star} b^{\star}$ color space results of PI-1a and PI-2a films. c Device transmittance of ITO/PI-1a/ electrolyte/ITO

more rapid counterion diffusion than PI-2a film, originated from the asymmetric pendant group ( $(N$-phenyl- $N$-phenyl) naphthalen-1-amine) and resulting loose chain stacking. In addition, the contrast ratios vs. pulse widths of PI-1a and PI-2a films were further depicted in Fig. $5 \mathrm{~b}$ for more direct comparison. Moreover, the switching $(1.3 \mathrm{~s})$ and bleaching $(1.1 \mathrm{~s})$ times of PI-1a are significantly slower than those of PI-2a films, plotted in Fig. 5b and summarized in Supplementary Table 2. The stability of transmittance change of PI-1a and PI-2a films were performed over 5000 cycles and shown in Supplementary Figure 16, indicating that the stability of PI-2a film is relatively higher than that of PI-1a.

Colorimetry. $L^{*} a^{\star} b^{\star}$ color space results for PI-1a and PI-2a films were presented in Fig. 6a, b. Both PI-1a and PI-2a films gave high $L^{\star}$ values (more than 99\%) in neutral states (see Fig. 6a), therefore, both films were highly transparent and colorless. In addition, oxidized PI-2a had a narrower, and unflat transmittance across the visible spectrum, which allowed unequal amounts of blue, green and red light to pass, thus gave a blue color. On the other hand, oxidized PI-1a film absorbed more blue light than PI2a film, exhibiting a flatter transmittance in the visible light region, thus gave a black stage and a lower $L^{*}$ value. Upon electrochemical oxidation, the $a^{\star} b^{\star}$ values of PI-1a film changed much smaller (from $(0.2,1.0)$ to $(-1.7,-0.7)$ ) than the those of PI-2a (from $(-3.5,-0.2)$ to $(-18,-18.7)$ ), as shown in Fig. 6b and Supplementary Table 3 ). The $L^{\star} a^{\star} b^{\star}$ color space results of PI1a and PI-2a films indicated that the colorless-to-black and blue switching electrochromes could be achieved. In addition, Supplementary Figure 18 showed the photographs of PI-1a and PI-2a films in fully oxidized states, which were performed on flexible monolayer graphene electrodes (the fabrication method of graphene electrode ${ }^{46,47}$ was described in Methods), which exhibited good coloration properties, indicative of their versatility on different electrodes.

\section{Discussion}

The two polyimides exhibited much higher contrast ratios than the previously reported ECPs, including conjugated polymers, polyimides and polynorbornenes ${ }^{18,20,48,49}$. Therefore, the difference between color points, denoted as $\Delta E_{a b}^{*}$, was calculated for determining the significance of color change observed by human eyes according to Eq. (3) $)^{33}$. The values of $\Delta E_{a b}^{*}$ for PI- 1 a and PI$2 \mathrm{a}$ between neutral states and oxidized states were calculated to be 79 and 49, respectively, indicating the more remarkable color change of PI-1a. The coloration efficiency of PI-1a film was also calculated to be $99 \mathrm{~cm}^{2} \mathrm{C}^{-1}$ by using Eq. (4), which is higher than that of PI-2a film $\left(78 \mathrm{~cm}^{2} \mathrm{C}^{-1}\right)$ due to the faster charge transfer in electrochemical system ${ }^{19}$. To further elaborate the high $\Delta \% T_{\text {int }}$ (integrated contrast ratio of transmittance changes) of PI-1a film, EC device of PI-1a was fabricated with device architecture of ITO/PI-1a/electrolyte/ITO ${ }^{50}$. The transmittance spectra of the device when PI-1a was in neutral and oxidized states are shown in Fig. 6c. The transmittance spectra revealed an ultrahigh integrated contrast ratio $\left(\Delta \% T_{\text {int }}\right)$ up to $80 \%$.

In summary, colorless-to-colorful EC polyimides with twisted and adjusted conjugated structures were prepared via architectural design. The $L^{\star} a^{\star} b^{\star}$ color space results of EC polyimide films indicated that the colorless-to-colorful switching electrochromes were achieved, which was very unique in the field of developing EC color display and optical areas. In particular, PI-1a and PI-2a films were colorless in visible region. On the other 
hand, PI-1a and PI-2a films exhibited black and blue colors in fully oxidized state, respectively. In addition, we also showed that the charge transfer behaviors were strongly depending on the chemical structures. Moreover, we proved that a fast counterion diffusion in PI-1a film due to the asymmetric structure, which resulted in loosely chain stacking morphology and fast EC responses. Therefore, the facile strategy in developing colorlessto-colorful EC polyimides are very attractive to the field of EC display and optical areas.

\section{Methods}

Basic characterization. The NMR measurements were carried out on a Bruker DRX-500 at $600 \mathrm{MHz}$ for ${ }^{1} \mathrm{H}$ NMR and $150 \mathrm{MHz}$ for ${ }^{13} \mathrm{C}$ NMR spectra. Absorption and transmittance spectra were performed on a JASCO-V-670 spectrophotometer. The background of ITO or glass (where the thin film were deposited) was subtracted when we tested the absorption and transmittance spectra of polymer films. Photoluminescence excitation spectra of polymer films were recorded on a HORIBA Jobin Yvon FluoroMax-3 spectrofluorometer. Cyclic voltammetry (CV) was conducted with $\mathrm{CHI}$ model 619A. ITO and a platinum wire were used as a working electrode and an auxiliary electrode, respectively. The CV and EC experiments were performed in a solution of $0.1 \mathrm{M}$ tetrabutylammonium perchlorate (TBAP)/acetonitrile $\left(\mathrm{CH}_{3} \mathrm{CN}\right)$ against a $\mathrm{Ag} / \mathrm{Ag}^{+}$reference electrode. High resolution fieldemission scanning electron microscope (SEM) images of polymer films were conducted on JEOL JSM-6500F. EIS measurements of polymer films were performed on BCS-815 with the frequency range of $10 \mathrm{mHz}-10 \mathrm{kHz}$. DPV of PI-1a and PI-2a films were performed on Autolab PGSTATE302 MBA. XRD was performed on D2 PHASER (BRUKER). SAXS was performed on an in-house Bruker Nanostar SAXS instrument. AFM was performed on Dimension Icon (BRUKER).

Film preparation. All the thin films described in this study were prepared in the following procedure: $10 \mathrm{mg}$ polyimides were dissolved in $1 \mathrm{ml} \mathrm{NMP}$; the solution was stirred at $85^{\circ} \mathrm{C}$ for $1 \mathrm{~h}$. Hundred microliters of the above solution was dropcast on a $2 \times 2 \mathrm{~cm}^{2}$ ITO-coated substrate and annealed at $85^{\circ} \mathrm{C}$ for $1 \mathrm{~h}$ and $110^{\circ} \mathrm{C}$ for another $1 \mathrm{~h}$ in sequence. All the procedures are carried out under ambient conditions. The films described in Fig. 1c, e were prepared using a more concentrated solution $\left(0.1 \mathrm{~g} \mathrm{ml}^{-3}\right)$ and the films for refractive index were deposited on silicon wafers. The thicknesses of PI-1a and PI-2a films are 730 and $360 \mathrm{~nm}$ for the measurement of EC experiments, SEM and AFM, respectively.

The preparation of CVD Graphene/PET films were described as follows. On a $25 \mathrm{~mm}$ copper foil (Alfa Aesar), we used CVD method to grow large-area fewlayered graphene. Before growth, we used plasma to remove the oxide layer of copper. At graphene growth temperature $\left(1000^{\circ} \mathrm{C}\right)$, we introduced a flow of 15 sccm $\mathrm{H}_{2}$ and $65 \mathrm{sccm} \mathrm{CH}_{4}$. After CVD growth of graphene, we used a transfer process with PMMA (15k, 4.6 wt\%) coating to transfer graphene electrode on to PET substrate. We use Ferric Nitride $\left(0.05 \mathrm{mg} \mathrm{ml}^{-1}\right)$ to etch away the copper foil substrate and the graphene/PMMA thin film was floating on etchant solution. We washed the PMMA film by D.I. water and transferred it onto PET substrates (with a sheet resistance of $\sim 1 \mathrm{k}-2 \mathrm{k} \Omega / \mathrm{sq}$ and a transmittance of $97.5 \%$ at $550 \mathrm{~nm}$ ). We also used absorption spectrum to confirm that less than three layers of graphene were formed on PET substrate, because the graphene/PET showed a transmittance of $94-97 \%$ at $550 \mathrm{~nm}$ and a monolayer graphene absorbed $\sim 2.3 \%$ transmittance at $550 \mathrm{~nm}$.

EC device fabrication. For the preparation of gel electrolyte of EC device, we mixed polyethylene glycol $(15 \mathrm{kDa})$ and $\mathrm{LiClO}_{4}$ (with a molar ratio of 8:1) and dissolved them in $25 \% \mathrm{w} / \mathrm{v}$ acetonitrile. The acetonitrile solvent was stirred and evaporated at $25^{\circ} \mathrm{C}$ before the polyethylene glycol precipitated. We placed a adhesive tape on the ITO $(2 \mathrm{~cm} \times 2 \mathrm{~cm})$ to form a frame and dropped the gel electrolyte within the adhesive tape frame. Then we placed the polyimide coated ITO glass face-down on the gel-coated slide, and pressed the two electrodes together using clips.

Diffusion coefficient. We analyzed the diffusion coefficient of counterion $\left(\mathrm{ClO}_{4}^{-}\right)$ in both PI-1a and PI-2a films according to the Randles-Sevcik equation, described as follows:

$$
i_{\mathrm{p}}=k n^{\frac{3}{2}} A D^{\frac{1}{2}} c v^{\frac{1}{2}}
$$

The current maximum value $\left(i_{\mathrm{p}}\right)$ of polymer film was proportional to the square root of scan rate $\left(v^{1 / 2}\right)$, the slope is $k n^{3 / 2} A D^{1 / 2} c$.

Film density. The film thicknesses mainly depended on the polymer chain stacking property and were inversely proportional to the film density:

$$
\text { Density }_{\text {polyimide }}=\frac{\text { Weight }_{\text {Film }}}{\text { Volume }_{\text {Film }}}=\frac{\text { Weight }_{\text {Film }}}{\text { Area }_{\text {Film }} \times \text { Thichkness }_{\text {Film }}}
$$

The calculation of polymer densities of PI-1a and PI-2a films were firstly cut off the edge of five pieces of polymer films (for each piece polymer film is one milligram) because the edge is thicker than the middle part (see Supplementary Figure 9), the resulting edge of five PI-1a and PI-2a films was weight to be 2.2 and $1.9 \mathrm{mg}$, respectively. The densities of PI-1a and PI-2a films were calculated according to Eq. (2):

$$
\begin{aligned}
& \text { Density }_{\mathrm{PI}-1 \mathrm{a}}=\frac{\text { total Weight }_{\mathrm{PI}-1 \mathrm{a}}(\text { five pieces })}{\text { total } \text { Volume }_{\mathrm{PI}-1 \mathrm{a}}(\text { five pieces })}=\frac{5.0 \mathrm{mg}-2.2 \mathrm{mg}}{9.344 \times 10^{-4} \mathrm{~cm}^{3}}=3.0 \mathrm{~g} \mathrm{~cm}^{-3} \\
& \text { Density }_{\mathrm{PI}-2 \mathrm{a}}=\frac{\text { total Weight }_{\mathrm{PI}-2 \mathrm{a}}(\text { five pieces })}{\text { total Volume }} \mathrm{PI}-2 \mathrm{a}_{\text {(five pieces })}=\frac{5.0 \mathrm{mg}-1.9 \mathrm{mg}}{4.608 \times 10^{-4} \mathrm{~cm}^{3}}=6.7 \mathrm{~g} \mathrm{~cm}^{-3}
\end{aligned}
$$

Difference between color points. The difference between color points, denoted as $\Delta E_{a b}^{*}$, was calculated for determining the significance of color change observed by human eyes, as following equation:

$$
\Delta E_{a b}^{*}=\sqrt{\left(\Delta L^{*}\right)^{2}+\left(\Delta a^{*}\right)^{2}+\left(\Delta b^{*}\right)^{2}}
$$

Coloration efficiency. The coloration efficiency of polyimide films were calculated according to the following equation:

$$
\text { Coloration Efficiency }=\frac{1}{Q} \log \frac{\tau_{b}}{\tau_{c}}
$$

where $Q$ is the insertion charges, and the $T_{\mathrm{b}}$ and $T_{\mathrm{c}}$ are transmittances of colored and bleached states of EC films.

\section{Data availability}

The data that support the findings of this study are available from the authors on reasonable request.

Received: 7 September 2018 Accepted: 13 February 2019

Published online: 18 March 2019

\section{References}

1. Mortimer, R. J., Rosseinsky, D. R. \& Monk, P. M. S. Electrochromic Materials and Devices. (Wiley-VCH Verlag GmbH \& Co. KGaA, Weinheim, Germany, 2015). https://doi.org/10.1002/9783527679850.ch5

2. Gunbas, G. E., Durmus, A. \& Toppare, L. Could green be greener? Novel donor-acceptor-type electrochromic polymers: towards excellent neutral green materials with exceptional transmissive oxidized states for completion of RGB color space. Adv. Mater. 20, 691-695 (2008).

3. Beaujuge, P. M. \& Reynolds, J. R. Color control in $\pi$-conjugated organic polymers for use in electrochromic devices. Chem. Rev. 110, 268-320 (2010).

4. Müllen, K., Reynolds, J. R. \& Masuda, T. Conjugated Polymers: A Practical Guide to Synthesis. (Royal Society of Chemistry, Cambridge, 2013).

5. Beaujuge, P. M., Ellinger, S. \& Reynolds, J. R. The donor-acceptor approach allows a black-to-transmissive switching polymeric electrochrome. Nat. Mater. 7, 795-799 (2008)

6. Shi, P. et al. Broadly absorbing black to transmissive switching electrochromic polymers. Adv. Mater. 22, 4949-4953 (2010).

7. Vasilyeva, S. V. et al. Material strategies for black-to-transmissive switching polymer electrochromic devices. ACS Appl. Mater. Interfaces 3, 1022-1032 (2011).

8. Ko, H. C., Kang, M., Moon, B. \& Lee, H. Enhancement of electrochromic contrast of poly(3,4-ethylenedioxythiophene) by incorporating a pendant viologen. Adv. Mater. 16, 1712-1716 (2004).

9. Sassi, M. et al. Gray to colorless switching, crosslinked electrochromic polymers with outstanding stability and transmissivity from naphthalenediimmide-functionalized EDOT. Adv. Mater. 24, 2004-2008 (2012)

10. Beverina, L., Pagani, G. A. \& Sassi, M. Multichromophoric electrochromic polymers: colour tuning of conjugated polymers through the side chain functionalization approach. Chem. Commun. 50, 5413-5430 (2014).

11. Sassi, M. et al. State-of-the-art neutral tint multichromophoric polymers for high-contrast see-through electrochromic devices. Adv. Funct. Mater. 26 5240-5246 (2016)

12. Alesanco, Y., Viñuales, A., Cabañero, G., Rodriguez, J. \& Tena-Zaera, R. Colorless-to-black/gray electrochromic devices based on a single 1-alkyl-1'aryl asymmetric viologen-modified monolayered electrodes. Adv. Opt. Mater. 5, 1600989 (2017)

13. Ling, Q. D. et al. Synthesis and dynamic random access memory behavior of a functional polyimide. J. Am. Chem. Soc. 128, 8732-8733 (2006). 
14. Lee, M. M., Teuscher, J., Miyasaka, T., Murakami, T. N. \& Snaith, H. J. Efficient hybrid solar cells based on meso-superstructured organometal halide perovskites. Science 338, 643-647 (2012).

15. Burschka, J. et al. Sequential deposition as a route to high-performance perovskite-sensitized solar cells. Nature 499, 316-319 (2013).

16. Zhang, Q. et al. Toward a universal polymeric material for electrode buffer layers in organic and perovskite solar cell and organic light-emitting diode. Energy Environ. Sci. 11, 682-691 (2018).

17. Lin, Q.-D. et al. Polymer electronic memories: materials, devices and mechanisms. Prog. Polym. Sci. 33, 917-978 (2008).

18. Chen, W. H., Wang, K. L., Liaw, D.-J., Lee, K. R. \& Lai, J. Y. $N, N, N^{\prime}, N$ '-tetraphenyl-1,4-phenylenediamine-fluorene alternating conjugated polymer: synthesis, characterization, and electrochromic application. Macromolecules 43, 2236-2243 (2010).

19. Zhang, Q. et al. Transmissive-to-black fast electrochromic switching from a long conjugated pendant group and a highly dispersed polymer/SWNT. Polym. Chem. 9, 619-626 (2018).

20. Lian, W.-R. et al. Neutrally colourless, transparent and thermally stable polynorbornenes via ring-opening metathesis polymerisation for nearinfrared electroactive applications. J. Mater. Chem. 21, 8597-8604 (2011)

21. Corrente, G. A. et al. Colorless to all-black full-NIR high-contrast switching in solid electrochromic films prepared with organic mixed valence systems based on dibenzofulvene derivatives. Chem. Mater. 30, 5610-5620 (2018).

22. Liu, H.-S. et al. Highly transparent to truly black electrochromic devices based on an ambipolar system of polyamides and viologen. NPG Asia Mater. 9, e388 (2017).

23. Liaw, D.-J. et al. Advanced polyimide materials: syntheses, physical properties and applications. Prog. Polym. Sci. 37, 907-974 (2012).

24. Abidin, T., Zhang, Q., Wang, K. L. \& Liaw, D. J. Recent advances in electrochromic polymers. Polym. (Guildf.). 55, 5293-5304 (2014).

25. Matsumoto, T. Nonaromatic polyimides derived from cycloaliphatic monomers. Macromolecules 32, 4933-4939 (1999).

26. Nakabayashi, K. et al. Poly(phenylene thioether)s with fluorene-based cardo structure toward high transparency, high refractive index, and low birefringence. Macromolecules 49, 5849-5856 (2016).

27. $\mathrm{Xu}, \mathrm{T}$. et al. High-contrast and fast electrochromic switching enabled by plasmonics. Nat. Commun. 7, 10479 (2016).

28. Matsuura, T, Ando, S. \& Sasaki, S. in Fluoropolymers 2, Ch. 14 (Springer, Boston, MA, 2002). .

29. Hasegawa, M., Kasamatsu, K. \& Koseki, K. Colorless poly(ester imide)s derived from hydrogenated trimellitic anhydride. Eur. Polym. J. 48, 483-498 (2012).

30. Nish, A., Hwang, J.-Y., Doig, J. \& Nicholas, R. J. Highly selective dispersion of single-walled carbon nanotubes using aromatic polymers. Nat. Nanotech. 2, 640-646 (2007).

31. Chiang, W. H. \& Sankaran, R. M. Linking catalyst composition to chirality distributions of as-grown single-walled carbon nanotubes by tuning $\mathrm{Ni}_{x} \mathrm{Fe}_{1-x}$ nanoparticles. Nat. Mater. 8, 882-886 (2009).

32. Sosorev, A. Y., Parashchuk, O. D., Zapunidi, S. A., Kashtanov, G. S. \& Paraschuk, D. Y. Intrachain aggregation of charge-transfer complexes in conjugated polymer: acceptor blends from photoluminescence quenching. J. Phys. Chem. C. 117, 6972-6978 (2013)

33. Kerszulis, J. A., Bulloch, R. H., Teran, N. B., Wolfe, R. M. W. \& Reynolds, J. R. Relax: a sterically relaxed donor-acceptor approach for color tuning in broadly absorbing, high contrast electrochromic polymers. Macromolecules 49, 6350-6359 (2016).

34. Skoog, D. A, Holler, F. J. \& Crouch, S. R. Principles of Instrumental Analysis, 6th edn. (Cengage Learning, MA, 2006).

35. McKeen, L. W. Fluorinated Coatings and Finishes Handbook. (William Andrew Publishing, Norwich, 2006).

36. Banerjee, S. Handbook of Specialty Fluorinated Polymers Preparation, Properties, and Applications. (Elsevier, Oxford, UK, 2015).

37. Ghosh, A., Sen, S. K., Banerjee, S. \& Voit, B. Solubility improvements in aromatic polyimides by macromolecular engineering. RSC Adv. 2, 5900-5926 (2012).

38. Kojio, K. et al. Simultaneous small-angle X-ray scattering/wide-angle X-ray diffraction study of the microdomain structure of polyurethane elastomers during mechanical deformation. Polym. J. 43, 692-699 (2011).

39. Bates, S. et al. Assessment of defects and amorphous structure produced in raffinose pentahydrate upon dehydration. J. Pharm. Sci. 96, 1418-1433 (2007).

40. Ivanisevic, I. Physical stability studies of miscible amorphous solid dispersions. J. Pharm. Sci. 99, 4005-4012 (2010).

41. Xiong, S. et al. Water-processable polyaniline with covalently bonded singlewalled carbon nanotubes: enhanced electrochromic properties and impedance analysis. ACS Appl. Mater. Interfaces 3, 782-788 (2011).
42. Mishra, S. et al. Fast electrochromic display: tetrathiafulvalene-graphene nanoflake as facilitating materials. J. Mater. Chem. C. 5, 9504-9512 (2017).

43. Moser, M. L. et al. Fast electrochromic device based on single-walled carbon nanotube thin films. Nano. Lett. 16, 5386-5393 (2016).

44. Iroh, J. O. \& Levine, K. Capacitance of the polypyrrole/polyimide composite by electrochemical impedance spectroscopy. J. Power Sources 117, 267-272 (2003).

45. Gu, J.-G., Cheng, S.-P., Liu, J. \& Gu, J.-D. A sensitive electrochemical impedance spectroscopy method for detection of polyimide degradation by microorganisms. J. Polym. Environ. 8, 167-174 (2000).

46. Loan, P. T. K. et al. Graphene/ $\mathrm{MoS}_{2}$ heterostructures for ultrasensitive detection of DNA hybridisation. Adv. Mater. 26, 4838-4844 (2014)

47. Docherty, C. J. et al. Extreme sensitivity of graphene photoconductivity to environmental gases. Nat. Commun. 3, 1228 (2012).

48. Chang, C. H. et al. Novel rapid switching and bleaching electrochromic polyimides containing triarylamine with 2-phenyl-2-isopropyl groups. Polym. (Guildf.). 51, 4493-4502 (2010).

49. Lian, W. R. et al. Flexible electrochromic devices based on optoelectronically active polynorbornene layer and ultratransparent graphene electrodes. Macromolecules 44, 9550-9555 (2011).

50. Wałęsa-Chorab, M. \& Skene, W. G. Visible-to-NIR electrochromic device prepared from a thermally polymerizable electroactive organic monomer. ACS Appl. Mater. Interfaces 9, 21524-21531 (2017).

\section{Acknowledgements}

We acknowledge the financial support of the Ministry of Science and Technology, Taiwan. All the authors thank Prof. Hsin-Lung Chen (National Tsing Hua University, Department of Chemical Engineering) and Mr. Yu-Hsuan Lin for the use of SAXS and XRD. We also thank Prof. Bing-Joe Hwang (National Taiwan University of Science and Technology, Department of Chemical Engineering) and his student Si-Xing Sun for the use of Dimension Icon (DPV and stability test). In addition, Dr. Wei-Ting Wang was also much appreciated for her kind assistance of the measurements of AFM, SAXS, and XRD of PI-Ia and PI-2a films. Finally, we thank Mitsubishi Gas Chemical and Nippon Fine Chemical for supplying the chemicals.

\section{Author contributions}

Q.Z. prepared the diamine monomers and polymers, performed the electrochemical and electrochromic experiments, identified the NMR data, wrote the manuscript draft. C.Y.T. synthesized the dianhydride monomer, identified the NMR data, performed the EIS experiments. L.J.L. prepared the graphene electrodes. D.J.L. designed the concept and chemical structures, supervised the experiments, interpreted the data and wrote the manuscript.

\section{Additional information}

Supplementary Information accompanies this paper at https://doi.org/10.1038/s41467019-09054-8.

Competing interests: The authors declare no competing interests.

Reprints and permission information is available online at http://npg.nature.com/ reprintsandpermissions/

Journal peer review information: Nature Communications thanks the anonymous reviewer(s) for their contribution to the peer review of this work

Publisher's note: Springer Nature remains neutral with regard to jurisdictional claims in published maps and institutional affiliations.

(i)

Open Access This article is licensed under a Creative Commons Attribution 4.0 International License, which permits use, sharing, adaptation, distribution and reproduction in any medium or format, as long as you give appropriate credit to the original author(s) and the source, provide a link to the Creative Commons license, and indicate if changes were made. The images or other third party material in this article are included in the article's Creative Commons license, unless indicated otherwise in a credit line to the material. If material is not included in the article's Creative Commons license and your intended use is not permitted by statutory regulation or exceeds the permitted use, you will need to obtain permission directly from the copyright holder. To view a copy of this license, visit http://creativecommons.org/ licenses/by/4.0/.

(c) The Author(s) 2019 